\title{
Mass transfer with complex chemical reactions
}

\section{Simultaneous absorption of $\mathrm{H}_{2} \mathrm{~S}$ and $\mathrm{CO}_{2}$ in solutions of alkanolamines}

\author{
H. Bosch, J.A.M. Kuipers, W.P.M. van Swaaij and G.F. Versteeg* \\ Department of Chemical Engineering, Twente University of Technology, PO Box 217. \\ 7500 AE Enschede, The Netherlands
}

\begin{abstract}
Received 20 January 1989
An absorption model has been developed which is able to calculate the simultaneous absorption rates (and corresponding enhancement factors) of two gaseous components into a reactive liquid. In the liquid phase multiple complex parallel reversible reactions may take place. This model, for example, can be used for design and development of gas-treating processes for the selective removal of hydrogen sulphide. Due to the implementation of an additional transformation of the spatial coordinate, the required computational time could be reduced substantially without loss of accuracy. The present model can be incorporated into an overall absorption module for column design and simulation. Experimentally determined simultaneous absorption rates of $\mathrm{H}_{2} \mathrm{~S}$ and $\mathrm{CO}_{2}$ in aqueous solutions of alkanolamines and mixtures of alkanolamines can be predicted satisfactorily well for the conditions where both gases have a mutual interaction on the respective rates. The experiments were carried out in a stirred vessel with a flat surface over a wide range of process conditions.
\end{abstract}

Kerwords: absorption; chemical reactions; mass transfer; model

\section{Introduction}

In the field of chemical engineering much effort has been invested in modelling and calculating the absorption rates of mass transfer of gaseous components accompanied by complex chemical reactions. For the absorption of a gas followed by a single irreversible first-order reaction, analytical solutions for the several mass transfer models are available ${ }^{1,2}$. In the case of reversible reactions or more complex kinetics these phenomena become rather complicated problems as the differential equations describing these processes can no longer be solved analytically.

Often linearization techniques were used in finding approximate analytical solutions (for examples, see Refs 3-5), however, Versteeg et al. ${ }^{6}$ have shown that these descriptions are valid for very specific situations and conditions only. Another possibility of calculating absorption rates is the application of numerical techniques $^{7-9}$, but solving the set of relevant differential equations usually requires considerable amounts of computational time ${ }^{10}$. Therefore the implementation of these numerical models into absorber calculation programs is severely restricted.

Recently, Versteeg et al..$^{611}$ presented an improved

* For more detailed information on the absorption software used contact: G.F. Versteeg, CEREC, Anna Bijnsstraat 24, 7552 NC Hengelo, The Netherlands

0950-4214/89/020075-09\$03.00

ब 1989 Butterworth \& Co (Publishers) Ltd. numerical technique for the solution of absorption of a gas accompanied by one or more complex reversible reactions, based on the discretization of the differential equations according to the method proposed by Baker and Oliphant ${ }^{12}$. Due to the implementation of an additional transformation of the spatial-coordinate, the number of grid points could be drastically reduced without a substantial loss of accuracy. Experimentally observed absorption rates of $\mathrm{CO}_{2}$ or $\mathrm{H}_{2} \mathrm{~S}$ into aqueous solutions of alkanolamines or mixtures of alkanolamines could be simulated satisfactorily.

In the present paper, simultaneous absorption of two gases into solutions in which several complex reversible reactions take place will be treated. Examples of some industrially important processes are presented in Westerterp et al..$^{2}$. A well known and frequently applied process in industry is the removal of the acid components $\mathrm{H}_{2} \mathrm{~S}$ and $\mathrm{CO}_{2}$ from sour natural gases by means of reversible absorption in liquids, acid-gas treating. The performance of this operation depends on the absorption characteristics of the solvents in addition to the mass transfer parameters of the gas-liquid contactor. The solvents usually are divided into two classes: the physical solvents (e.g. selexol and purisol), in which the acid components are absorbed physically and chemical solvents (e.g. aqueous alkanolamine solutions) in which the presence of a basic reactant provides both increase in absorption capacity and enhancement of the mass 


\begin{tabular}{|c|c|c|c|}
\hline \multicolumn{4}{|c|}{ Nomenclature } \\
\hline$A$ & Component A & $\gamma$ & Stoichiometric coefficient \\
\hline$B$ & Component B & $\sigma$ & Local selectivity defined by Equation (16) \\
\hline$C$ & Component $\mathrm{C}$ & & \\
\hline$D$ & Component D & \multirow{2}{*}{\multicolumn{2}{|c|}{ Subscripts }} \\
\hline$D_{\text {subscript }}$ & Diffusivity $\left(\mathrm{m}^{2} \mathrm{~s}^{-1}\right)$ & & \\
\hline$E_{\text {subscript }}$ & Enhancement factor & & Component a \\
\hline$g$ & Gas phase & A, a & Component $\mathrm{b}$ \\
\hline$J$ & Molar flux $\left(\mathrm{mol} \mathrm{m}^{-2} \mathrm{~s}^{-1}\right)$ & $\begin{array}{l}\text { D } \\
\text { bulk }\end{array}$ & Concentration at bulk conditions \\
\hline$k_{\mathrm{G}}$ & $\begin{array}{l}\text { Gas phase mass transfer coefficient } \\
\left(\mathrm{m} \mathrm{s}^{-1}\right)\end{array}$ & c & Component $\mathrm{c}$ \\
\hline \multirow[t]{2}{*}{$k_{\mathrm{L}}$} & Liquid phase mass transfer coefficient & $\begin{array}{l}d \\
g\end{array}$ & $\begin{array}{l}\text { Component d } \\
\text { Gas phase }\end{array}$ \\
\hline & $\left(\mathrm{m} \mathrm{s}^{-1}\right)$ & & $\begin{array}{l}\text { Gas pnase } \\
\text { Species i }\end{array}$ \\
\hline$k_{\text {subscript }}$ & $\begin{array}{l}\text { Reaction rate constant } \\
\text { Liquid phase }\end{array}$ & int & Gas-liquid interface \\
\hline \multirow[t]{2}{*}{$m$} & $\begin{array}{l}\text { Liquid phase } \\
\text { Dimensionless solubility defined as }\end{array}$ & & $\begin{array}{l}\text { Species } \mathrm{j} \\
\text { Liguid phase }\end{array}$ \\
\hline & $\left.[A]_{\mathrm{l}} /[A]\right]_{\mathrm{g}}$ & $\mathrm{m}$ & $\begin{array}{l}\text { Liquid pnase } \\
\text { Reaction order }\end{array}$ \\
\hline$n$ & Number of reactions & $\mathrm{n}$ & Reaction order \\
\hline$n s$ & Number of spatial grid points & $\mathrm{p}$ & Reaction order \\
\hline$n t$ & Number of time grid points & & Reaction order \\
\hline$R$ & Reaction rate $\left(\mathrm{mol} \mathrm{m}^{-3} \mathrm{~s}^{-1}\right)$ & & Reaction order \\
\hline \multirow[t]{2}{*}{$S$} & Selectivity factor defined by & $\mathrm{s}$ & Reaction order \\
\hline & Equation (17) & $\mathrm{t}$ & Reaction order \\
\hline$t$ & Time $(\mathrm{s})$ & & Reaction order \\
\hline$x$ & Spatial coordinate $(\mathrm{m})$ & 0 & Equilibrium composition \\
\hline$y$ & Transformed spatial coordinate (1) & 1 & Gas phase component 1 \\
\hline \multirow{2}{*}{\multicolumn{2}{|c|}{ Greek letters }} & 2 & Gas phase component 2 \\
\hline & & $\mathrm{CO}_{2}$ & $\mathrm{CO}_{2}$ \\
\hline$\alpha$ & Solute loading defined by $[A]_{\mathrm{t}} /[B]_{\mathrm{t}}$ & $\mathrm{H}_{2} \mathrm{~S}$ & $\mathrm{H}_{2} \mathrm{~S}$ \\
\hline
\end{tabular}

transfer rate. In the present study attention will be paid to the description and calculation of the simultaneous absorption rates of two gases into a liquid where several complex, parallel reversible reactions occur.

Several approximate analytical solutions are available in the literature for the calculation of the mass transfer rate of two gas components with two irreversible reactions ${ }^{13-15}$, however, as already mentioned before, these models are only valid for specific conditions. Cornelissen ${ }^{16}$ published a numerical model based on the film theory but one of the liquid reactions was considered to be irreversible. For the simultaneous absorption of $\mathrm{H}_{2} \mathrm{~S}$ and $\mathrm{CO}_{2}$ into aqueous solutions of a primary or secondary amine, Cornelisse $e t a l .^{9}$ presented an absorption model solved numerically with a discretization technique in which interacting liquid phase reactions were taken into account. Unfortunately, the applicability of the latter model is restricted to a few stoichiometric schemes.

According to the numerical method presented by Versteeg et al. ${ }^{6,11}$, a model was developed for simultaneous mass transfer of two gas components accompanied by complex reversible reactions. Special attention has been paid to the computational time required to obtain satisfactory accurate absorption rates and possible implementation in absorber models. The model will be experimentally tested by comparison of absorption experiments of $\mathrm{CO}_{2}$ and $\mathrm{H}_{2} \mathrm{~S}$ into aqueous solutions (mixtures) of alkanolamines. The removal of these acid components from gases by alkanolamines in aqueous or mixed solvents has become a well-established process during the last decade and will gain even more importance in the near future.

\section{Theory}

The problem considered is mass transfer of two gaseous components accompanied by complex reversible parallel reactions. The reactions can be presented schematically by:

$A_{1}(\mathrm{~g})+\gamma_{1, b, j} B_{i}(\mathrm{l}) \rightleftarrows \gamma_{1, c, i} C_{i}(\mathrm{l})+\gamma_{1, d, i} D_{i}(\mathrm{l})$

for gas component 1

$A_{2}(\mathrm{~g})+\gamma_{2, b, i} B_{i}(\mathrm{l}) \rightleftarrows \gamma_{2, c, i} C_{i}(\mathrm{l})+\gamma_{2, d, i} D_{i}(1)$

for gas component 2

for $i=1,2,3, \ldots, n$ reactions.

With the following reaction rate equations for both components $A_{1}$ and $A_{2}$ :

$$
\begin{aligned}
\boldsymbol{R}_{\mathrm{A}}= & k_{m_{i}, n_{i}, p_{i}, q_{i}}[A]^{m_{i}}\left[B_{i}\right]^{n_{i}}\left[C_{i}\right]^{p_{i}}\left[D_{i}\right]^{q_{i}} \\
& -k_{r_{i}, t_{i}, s_{i}, v_{i}}[A]^{r_{i}}\left[B_{i}\right]^{s_{i}}\left[C_{i}\right]^{t_{i}}\left[D_{i}\right]^{v_{i}}
\end{aligned}
$$

for $i=1,2,3, \ldots, n$ reactions.

The occurrence of a common reaction product, say $D$, can be taken into account. An example of this situation is the simultaneous absorption of $\mathrm{H}_{2} \mathrm{~S}$ and $\mathrm{CO}_{2}$ in an alkanolamine solution in which the protonated amine is the common product for both reactions. Also, it is possible that between the liquid phase reactants and products 
additional reactions take place presented schematically by:

$B_{i}(1)+\gamma_{d, j}^{\prime} D_{j}(1) \rightleftarrows \gamma_{b, j}^{\prime} B_{j}(1)+\gamma_{d, i}^{\prime} D_{i}(\mathrm{l})$

for $j=1,2,3, \ldots, n$ and $j \neq i$

for $i=1,2,3, \ldots, n$

A typical example of an interaction reaction can be observed if $\mathrm{CO}_{2}$ is absorbed in a mixture of methylmonoethanolamine (MMEA) and dimethylethanolamine (MDEA) the interaction reactions (4) reduce to one single reaction which is extremely fast as it involves only a proton transfer. Therefore this reaction can be regarded as an equilibrium reaction:

MDEA + $\mathrm{MMEAH}^{+} \leftrightarrow \mathrm{MDEAH}^{+}+\mathrm{MMEA}^{-}$

Intcraction reactions likc (4) can bc incorporated into the mass transfer model.

For the description of mass transfer followed by chemical reaction the penetration model has been applied for the liquid phase because this model is generally accepted as the most realistic one ${ }^{27}$. For the gas phase, mass transfer was described with the stagnant film model.

According to the penetration model the material balance for each species yields the following set of partial differential equations:

$\frac{\partial\left[A_{1}\right]}{\partial t}=D_{A_{1}} \frac{\partial^{2}\left[A_{1}\right]}{\partial x^{2}}-\sum_{i=1}^{n} R_{A_{1}, i}$
$\frac{\partial\left[A_{2}\right]}{\partial t}=D_{A_{2}} \frac{\partial^{2}\left[A_{2}\right]}{\partial x^{2}}-\sum_{i=1}^{n} R_{A_{2}, i}$

$\frac{\partial\left[B_{i}\right]}{\partial t}=D_{B, i} \frac{\partial^{2}\left[B_{i}\right]}{\partial x^{2}}-\gamma_{1, b, i} R_{A_{1}, i}-\gamma_{2, b, i} R_{A_{2}, i}$

$\frac{\partial\left[C_{i}\right]}{\partial t}=D_{C, i} \frac{\partial^{2}\left[C_{i}\right]}{\partial x^{2}}+\gamma_{1, c, i} R_{A_{1, i}}+\gamma_{2, c, i} R_{A_{2}, i}$

$\frac{\partial\left[D_{i}\right]}{\partial t}=D_{D, i} \frac{\partial^{2}\left[D_{i}\right]}{\partial x^{2}}+\gamma_{1, d, i} R_{A_{1}, i}+\gamma_{2, d, i} R_{A_{2}, i}$

for $i=1,2,3, \ldots, n$ reactions.

To solve this set of differential equations uniquely, one initial and two boundary conditions are necessary for each differential equation. As the initial condition it is assumed that the system considered is in equilibrium for given solute loading:

$t=0$ and $x \geqslant 0$

$\left[A_{1}\right]=\left[A_{1}\right]_{0}$

$\left[A_{2}\right]=\left[A_{2}\right]_{0}$

$\left[B_{i}\right]=\left[B_{i}\right]_{0}$

$\left[C_{i}\right]=\left[C_{i}\right]_{0}$ and

$\left[D_{i}\right]=\left[D_{i}\right]_{0}$

for $i=1,2,3, \ldots, n$.

The first boundary condition, for $x=\infty$, can also be derived with the assumption of chemical equilibrium for the bulk of the liquid for given solute loading:

$t \geqslant 0$ and $x=\infty$

$\left[A_{1}\right]=\left[A_{1}\right]_{0}$

$\left[A_{2}\right]=\left[A_{2}\right]_{0}$

$\left[B_{i}\right]=\left[B_{i}\right]_{0}$

$\left[C_{i}\right]=\left[C_{i}\right]_{0}$

and

$\left[D_{i}\right]=\left[D_{i}\right]_{0}$

for $i=1,2,3, \ldots, n$.

The second boundary condition is obtained by assuming that the species $B_{i}, C_{i}$ and $D_{i}$ are non-volatile and that for $A$ at the interface the flux in the gas phase is equal to the flux in the liquid phase. The use of Equation (12) as boundary condition instead of an input parameter $\left[A_{i}\right]_{\mathrm{L} \text {, bulk }}$ has the advantage that, for situations with a noticeable amount of mass transfer limitations in the gas phase, the absorption rate can be calculated without the necessity of performing additional iterations to obtain the interfacial concentration of component $A$. The assumption of non-volatility is not necessary if all occurring reactions can be regarded as instantaneous with respect to mass transfer ${ }^{6}$ :

$k_{\mathrm{G}, \mathrm{A}_{1}}\left(\left[A_{1}\right]_{\mathrm{G}, \text { bulk }}-\left[A_{1}\right]_{\mathrm{G}, \text { int }}\right)=-D_{\mathrm{A}}\left(\frac{\partial\left[A_{1}\right]}{\partial x}\right)_{x=0}$
$k_{\mathrm{G}, \mathrm{A}_{2}}\left(\left[A_{2}\right]_{\mathrm{G}, \text { bulk }}-\left[A_{2}\right]_{\mathrm{G}, \text { int }}\right)=-D_{\mathrm{A}}\left(\frac{\partial\left[A_{2}\right]}{\partial x}\right)_{x=0}$

$\left(\frac{\partial\left[B_{i}\right]}{\partial x}\right)_{x=0}=\left(\frac{\partial\left[C_{i}\right]}{\partial x}\right)_{x=0}=\left(\frac{\partial\left[D_{i}\right]}{\partial x}\right)_{x=0}=0$

The approach used to solve these models consisted of the methodology presented by Cornelisse et al. ${ }^{9}$ and Versteeg et al. ${ }^{6}$. The sets of partial differential equations were numerically solved according to the discretization technique proposed by Baker and Oliphant ${ }^{12}$. To minimize the computation time and increase the accuracy an additional transformation of the spatial coordinate was introduced:

$y=\operatorname{erf}\left(x\left[4 D_{\max }\right]^{-1 / 2}\right)$

where $D_{\max }$ is the diffusivity with highest value. For a detailed description of the numerical technique used the reader is referred to Reference 6. 


\section{Experimental}

The models which were numerically solved in the present study have been experimentally tested by means of the simultaneous absorption of $\mathrm{H}_{2} \mathrm{~S}$ and $\mathrm{CO}_{2}$ in aqueous solutions (mixtures) of alkanolamines. The experiments were carried out in a stirred vessel operated under such conditions that the gas-liquid interface appeared visually to be completely smooth and, therefore, well defined. The experimental set-up was identical to the one used by Blauwhoff and van Swaaij ${ }^{10}$; for detailed information the reader is referred to this work.

The mass transfer coefficients, $k_{\mathrm{G}}$ and $k_{\mathrm{L}}$, of this stirred vessel were determined from physical $\mathrm{N}_{2} \mathrm{O}$ absorption with the assumption of the $\mathrm{CO}_{2}-\mathrm{N}_{2} \mathrm{O}$ analogy (Laddha et $a l .^{18}$ ) and by means of absorption of very diluted $\mathrm{H}_{2} \mathrm{~S}$ into the amine solution under investigation, respectively. The physico-chemical properties, solubility and diffusivity, of both acid gases were obtained either by means of the $\mathrm{CO}_{2}-\mathrm{N}_{2} \mathrm{O}$ analogy or estimated with a modified Stokes-Einstein relation ${ }^{19}$. For the ionic products, the diffusivity has been given the same value for each species and the values were taken equal to the component with the lowest diffusivity. The equilibrium composition of the liquid phase was calculated according to the method proposed by Blauwhoff and van Swaaij ${ }^{20}$.

The reaction between $\mathrm{H}_{2} \mathrm{~S}$ and alkanolamines can be regarded as an instantaneous equilibrium reaction with respect to mass transfer as it involves only a proton transfer [Equation (14)] and was approximated by very high $\left(\geqslant 10^{10}\right)$ reaction rate constants. The constants for the reverse reaction were estimated from the assumption that at equilibrium forward and reverse reaction rates are equal.

$$
\mathrm{H}_{2} \mathrm{~S}+\text { amine } \rightleftarrows \mathrm{HS}^{-}+\text {amineH}^{+}
$$

For the reaction of $\mathrm{CO}_{2}$ with the various alkanolamines the rate expression is usually rather complex ${ }^{21.22}$ and therefore it was approximated with:

$\vec{R}_{\mathrm{CO}_{2}}=k_{1, \mathrm{n}}\left[\mathrm{CO}_{2}\right]$ [amine $]^{n}$

Owing to the small variations of the amine concentration during the experiments and low solute loading the deviation of this rate expression could be neglected. The reverse reaction rate was calculated similar to that for the $\mathrm{H}_{2} \mathrm{~S}$ reaction. For the various amines the reaction constant was calculated according to Blauwhoff $e t$ al. ${ }^{23}$ and Versteeg and van Swaaij ${ }^{21.22}$.

\section{Results}

It is clear that it is impossible to present an extensive number of simulations owing to the large number of reactions and parameters which can be varied. Therefore, only a few typical situations and processes have been studied. Possible applications of these mass transfer models are demonstrated below.

In previous work ${ }^{6}$ these models were experimentally verified for the absorption of $\mathrm{CO}_{2}$ or $\mathrm{H}_{2} \mathrm{~S}$ into aqueous alkanolamine solutions. Mass transfer accompanied by parallel reactions has been checked by means of the absorption of $\mathrm{CO}_{2}$ into aqueous solutions of mixtures of alkanolamines ${ }^{11}$. Versteeg et al. were able to predict the observed absorption rates satisfactorily with deviations up to $30 \%$. In this work the model will be tested for the simultaneous absorption of $\mathrm{H}_{2} \mathrm{~S}$ and $\mathrm{CO}_{2}$ into aqueous solutions (of mixtures) of alkanolamines.

\section{Numerical results}

The applicability of numerically solved mass transfer models for purposes other than purely academic issues, for example, the implementation in column calculation and design, depends mainly on the amount of computation time required. Therefore, the first aim was to minimize this time without loss of accuracy. This aspect was achieved by means of an additional spatial transformation according to Equation (13). In Table 1 the effect of this transformation on the number of grid points and the accuracy is demonstrated for the simultaneous absorption of $\mathrm{H}_{2} \mathrm{~S}$ and $\mathrm{CO}_{2}$ into an aqueous MDEA solution and into an aqueous mixture of MDEA and MEA, respectively. The temperature was $298 \mathrm{~K}$ and both solutions consisted of a total amine concentration of $2000 \mathrm{~mol} \mathrm{~m}^{-3}$.

The physico-chemical constants needed for the simulations were taken from the literature. Data on reaction rate constants presented by Versteeg and van Swaaij ${ }^{21.22}$; solubility and diffusivity of the various components estimated according to Versteeg and van Swadij ${ }^{19}$; equilibrium composition of the liquid bulk calculated similar to the method proposed by Blauwhoff and van Swaaij $^{20}$.

From this table it can be concluded that for engineering purposes a grid consisting of $12 * 12$ up to $20 * 20$ points is sufficiently accurate to estimate the absorption rates and enhancement factors. Versteeg et al. reported in Reference 6 that a model solved without this additional transformation required a grid of at least $60 * 60$ points. It should be noted that the absorption model developed in the present study consists completely of tailor-made modules to solve the relevant equations. The use of library routines increases substantially the amount of computational time needed.

The computational time required on a Digital DEC2060 for one absorption calculation is acceptably low to use this mass transfer model for column calculations. The time needed to perform one calculation on the aforementioned mainframe computer is of the same magnitude as the time consumed by a Vax Station 2000 and about three times lower than a personal computer, without mathematical co-processor (Tulip at 386). The models are written in (Turbo-) Pascal and Fortran.

Table 1 Influence of the number of grid points on the accuracy and computation time

\begin{tabular}{|c|c|c|c|c|c|c|c|}
\hline \multicolumn{5}{|c|}{ MDEA + MEA solution } & \multicolumn{3}{|c|}{ MDEA solution } \\
\hline$n s$ & $n t$ & $E_{\mathrm{H}_{2} \mathrm{~S}}$ & $E_{\mathrm{CO}_{2}}$ & Time $(s)^{a}$ & $E_{\mathrm{H}_{2} \mathrm{~S}}$ & $E_{\mathrm{CO}_{2}}$ & Time $(\mathbf{s})^{a}$ \\
\hline 100 & 100 & 20.75 & 1.09 & 376 & - & - & - \\
\hline 70 & 70 & 20.75 & 1.09 & 186 & - & - & - \\
\hline 60 & 60 & - & - & - & 18.80 & 1.28 & 62 \\
\hline 50 & 50 & 20.75 & 1.09 & 94 & - & - & - \\
\hline 40 & 40 & 20.75 & 1.09 & 60 & - & - & - \\
\hline 30 & 30 & 20.76 & 1.09 & 44 & 18.80 & 1.27 & 16.8 \\
\hline 26 & 26 & 20.76 & 1.09 & 27 & - & - & - \\
\hline 20 & 20 & 20.77 & 1.10 & 15.7 & 18.80 & 1.27 & 7.02 \\
\hline 16 & 16 & 20.79 & 1.10 & 9.61 & - & - & - \\
\hline 12 & 12 & 20.84 & 1.12 & 5.63 & 18.90 & 1.28 & 2.42 \\
\hline 8 & 8 & 21.07 & 1.19 & 2.63 & 19.30 & 1.36 & 0.96 \\
\hline 6 & 6 & 21.47 & 1.34 & 1.53 & 19.80 & 1.52 & 0.42 \\
\hline
\end{tabular}

a Calculations performed on a Digital mainframe DEC2060 
Cornelisse et al ${ }^{9}$ developed a model for the description of the simultaneous absorption of $\mathrm{H}_{2} \mathrm{~S}$ and $\mathrm{CO}_{2}$ into aqueous solutions of primary or secondary alkanolamines. They observed that for very specific conditions one of the gases was desorbed from the solution although from the direction of the driving force it was expected that absorption would prevail. This effect was called forced desorption. Blauwhoff and van Swaaij verified experimentally this phenomenon in Reference 10 . One can regard this desorption behaviour as an extreme test of the present absorption model. Therefore, calculations were carried out for the absorption of $\mathrm{H}_{2} \mathrm{~S}$ and $\mathrm{CO}_{2}$ into an aqueous mixture of MEA and MDEA for forced desorption conditions, at $298 \mathrm{~K} \quad[\mathrm{MEA}]=20 \mathrm{~mol} \mathrm{~m}^{-3}$ and $[\mathrm{MDEA}]=1980 \mathrm{~mol} \mathrm{~m}^{-3}$. During the simulations the number of grid points was varied. In Table 2 the results of the calculations are presented and the concentration profiles are given in Figure 1. It should be noted that in Figure 1 dimensionless concentration profiles are plotted, the liquid phase reactants are normalized on their respective total amine-concentrations and the gas-phase reactants and their reaction products on the respective gas bulk concentrations. From these results it can be concluded that even for extreme conditions a grid consisting of about 200 points is sufficient to obtain satisfactory accurate results, but it is advisable to distribute the points equally over spatial and time coordinates.

\section{Selective removal of $\mathrm{H}_{2} \mathrm{~S}$}

In acid gas-treating processes usually only the removal of $\mathrm{H}_{2} \mathrm{~S}$ is necessary and the coabsorption of $\mathrm{CO}_{2}$ can be regarded as undesirable. Therefore, it is in many situations economically attractive to remove $\mathrm{H}_{2} \mathrm{~S}$ selectively from these gas streams, see, for example, McEwan and Marmin $^{24}$, and Kohl and Riesenfeld ${ }^{25}$. A yardstick to express the selectivity of a treating process is Equation (16):

$\sigma_{\text {local }}=\frac{\text { rate of absorption of } \mathrm{H}_{2} \mathrm{~S}}{\text { rate of absorption of } \mathrm{CO}_{2}}=\frac{J_{\mathrm{H}_{2} \mathrm{~S}}}{J_{\mathrm{CO}_{2}}}$

The values of these local selectivities depend heavily on the magnitudes of the driving forces of both $\mathrm{CO}_{2}$ and $\mathrm{H}_{2} \mathrm{~S}$. Therefore, a selectivity factor $S$ is defined which is corrected for the influences of the concentrations:

$S=\frac{\left(\frac{\text { rate of absorption of } \mathrm{H}_{2} \mathrm{~S}}{\text { driving force of } \mathrm{H}_{2} \mathrm{~S}}\right)}{\left(\frac{\text { rate of absorption of } \mathrm{CO}_{2}}{\text { driving force of } \mathrm{CO}_{2}}\right)}$

The rate of absorption can be calculated according to Equation (18):

$J_{\mathrm{A}}=\frac{[A]_{\mathrm{G}, \text { bulk }}-\frac{[A]_{\mathrm{L}, \text { bulk }}}{m_{\mathrm{A}}}}{\frac{1}{k_{\mathrm{G}}}+\frac{1}{m_{\mathrm{A}} E_{\mathrm{A}} k_{\mathrm{L}}}}$

Unfortunately, the calculation of the rates of absorption for the simultaneous absorption of $\mathrm{H}_{2} \mathrm{~S}$ and $\mathrm{CO}_{2}$ according to Equation (18) is not simple and straightforward, as already mentioned. However, for a few experimental conditions it is possible to derive asymptotic, simple
Table 2 Influence of the number of grid points on the accuracy and computation time for forced desorption conditions in an aqueous mixture of MDEA and MEA

\begin{tabular}{|rrrrc|}
\hline$n s$ & $n t$ & $E_{\mathrm{H}_{2} \mathrm{~S}}$ & $E_{\mathrm{CO}_{2}}$ & Time(s) \\
\hline 70 & 70 & 8.779 & -61.361 & 186 \\
40 & 40 & 8.769 & -61.475 & 61 \\
20 & 20 & 8.848 & -61.591 & 15.5 \\
20 & 10 & 9.414 & -66.146 & 7.69 \\
10 & 20 & 9.027 & -64.669 & 7.85 \\
14 & 14 & 8.942 & -62.208 & 7.61 \\
12 & 12 & 9.009 & -62.332 & $\mathbf{5 . 5 9}$ \\
10 & 10 & 9.581 & -61.555 & 3.93 \\
16 & 6 & 10.920 & -67.054 & 3.79 \\
6 & 16 & 10.665 & -74.807 & 3.81 \\
8 & 8 & 10.821 & -15.104 & 2.55 \\
6 & 6 & 12.165 & -49.490 & 1.45 \\
\hline
\end{tabular}

${ }^{8}$ Calculations performed on a Digital mainframe DEC2060

expressions. For conditions that the absorption of $\mathrm{H}_{2} \mathrm{~S}$ and $\mathrm{CO}_{2}$ has a negligible mutual interaction, realized at very low gas phase concentrations, the $\mathrm{H}_{2} \mathrm{~S}$ mass transfer usually is entirely gas phase controlled and the $\mathrm{CO}_{2}$ absorption is both gas and liquid phase limited. It should be noted that the reaction between $\mathrm{CO}_{2}$ and the alkanolamine should not be too fast otherwise the instantaneous reaction regime will be reached which consequently will affect the $\mathrm{H}_{2} \mathrm{~S}$ rate. If these conditions are obeyed, Equation (18) can be simplified leading to:

$S=\frac{k_{\mathrm{G}, \mathrm{H}_{2} \mathrm{~S}}}{k_{\mathrm{G}, \mathrm{CO}_{2}}}+\frac{k_{\mathrm{G}, \mathrm{H}_{2} \mathrm{~S}}}{m_{\mathrm{CO}_{2}} E_{\mathrm{CO}_{2}} k_{\mathrm{L}}}$

Plotting the experimentally determined values of $S$ as a function of $k_{\mathrm{G}, \mathrm{H}_{2} \mathrm{~S}}$, with constant value for $k_{\mathrm{L}}$, should yield a straight line. The slope of this line can be regarded as a measure for the selectivity of the solvent and contactor combination studied.

For the regime of negligible mutual interaction it is possible to screen solvents on their suitability for selective removal of $\mathrm{H}_{2} \mathrm{~S}$. These experiments preferably should be carried out in model gas-liquid contactors with a known and well defined interfacial area, for example, stirred cell, laminar jet and wetted sphere. Blauwhoff and van Swaaij $^{10}$ demonstrated for an aqueous di-isopropanolamine (DIPA) solution that the selectivity factor increased with $k_{\mathrm{G}}$ according to Equation (19). Their experiments were performed in a stirred cell and a laminar film reactor.

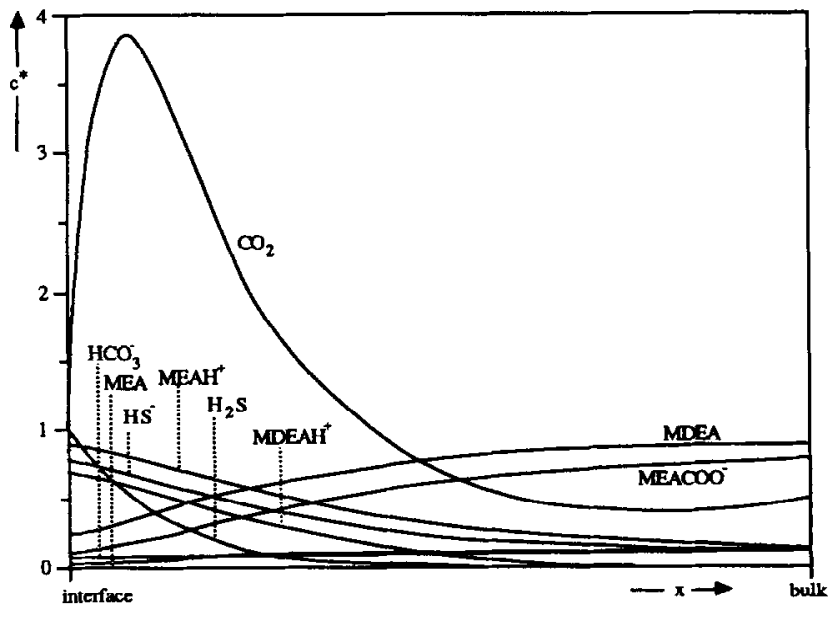

Figure 1 Dimensionless concentration profiles at the end of the contact time for the simultaneous absorption of $\mathrm{CO}_{2}$ and $\mathrm{H}_{2} \mathrm{~S}$ into a mixture of MEA and MDEA 
In the present study additional experiments have been carried out in the same set-up for aqueous solutions of di-ethanolamine (DEA), MDEA, MEA and DIPA. The observed selectivity factors are presented in Figure 2 where also the data of Blauwhoff and van Swaaij ${ }^{10}$ are included. Unfortunately, for the MEA solution it was not possible to perform experiments in the regime of negligible interaction and, therefore, these results were omitted from Figure 2. From the peculiar behaviour of $S$ for the solution [DIPA] $=2400 \mathrm{~mol} \mathrm{~m}^{-3}$ it can be concluded that also for this solvent the assumption of no interaction probably was not fulfilled. This latter result demonstrates directly that it is necessary to have information on the reaction kinetics and mass transfer parameters of the set-up beforehand.

A serious disadvantage of the above-mentioned screening method is that in model reactors with welldefined interfacial areas only a small variation of the magnitude of the gas phase mass transfer coefficient can be realized. Moreover, these values of $k_{\mathrm{G}}$ usually differ substantially from those to be expected in commercially used contactors (for example, trays and packed columns) resulting in an uncertainty owing to the extrapolation of $S$. Furthermore the selectivity factor determined according to Equation (19) is only valid for low gas phase concentrations which for practical situations only occur at the top of the absorber. However, if the aforementioned mass transfer model is used no restrictions are imposed on interaction and gas and/or liquid phase mass transfer limitation and concentration levels, respectively.

In Figures 3 and 4 the outcome of selectivity calculations from the model are presented for four aqueous amine solutions (MDEA, DIPA, MEA and amino-methylpropanol [AMP]) with a concentration of $2000 \mathrm{~mol} \mathrm{~m}^{-3}$. For detailed information on the concentrations during the simulations see Table 3. In Figure 3 the selectivity factor is plotted as function of $k_{\mathrm{G}}$ for the MDEA solution with $k_{\mathrm{L}}$ as parameter. From this figure it can be concluded that for small values of $k_{\mathrm{G}}$ for all simulations $S$ is nearly equal to 1 , i.e. the selectivity which can be reached with gas phase limitation for both components. Increasing $k_{\mathrm{G}}$ leads to higher values of $S$ until a maximum is reached and then $S$ remains constant although $k_{\mathrm{G}}$ is still increased. For the latter asymptotic situation the absorption of $\mathrm{CO}_{2}$ and $\mathrm{H}_{2} \mathrm{~S}$ is liquid phase limited resulting in considerable mutual

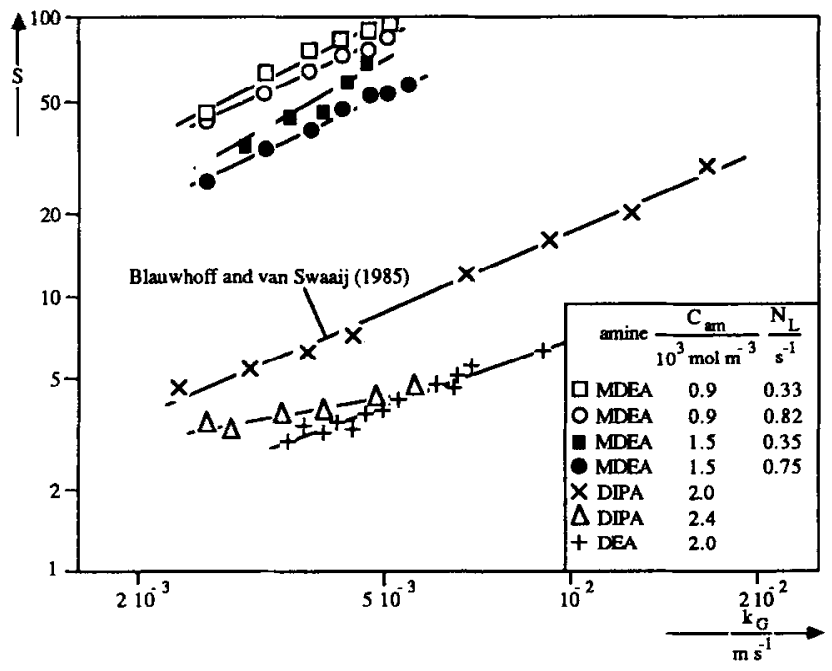

Figure 2 Experimentally determined selectivity factors for several aqueous alkanolamine solutions

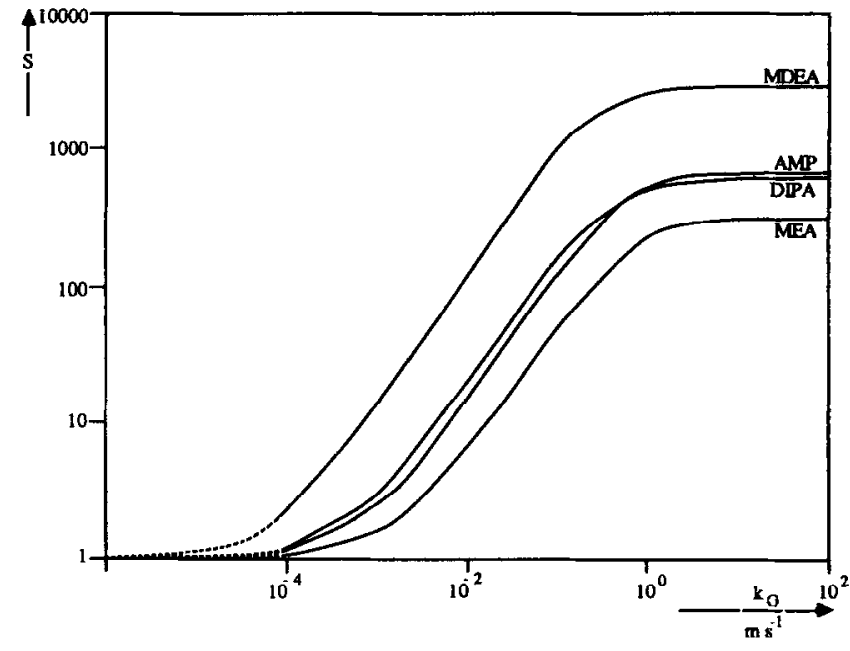

Figure 3 Selectivity factors for several aqueous amine solutions calculated with the absorption model

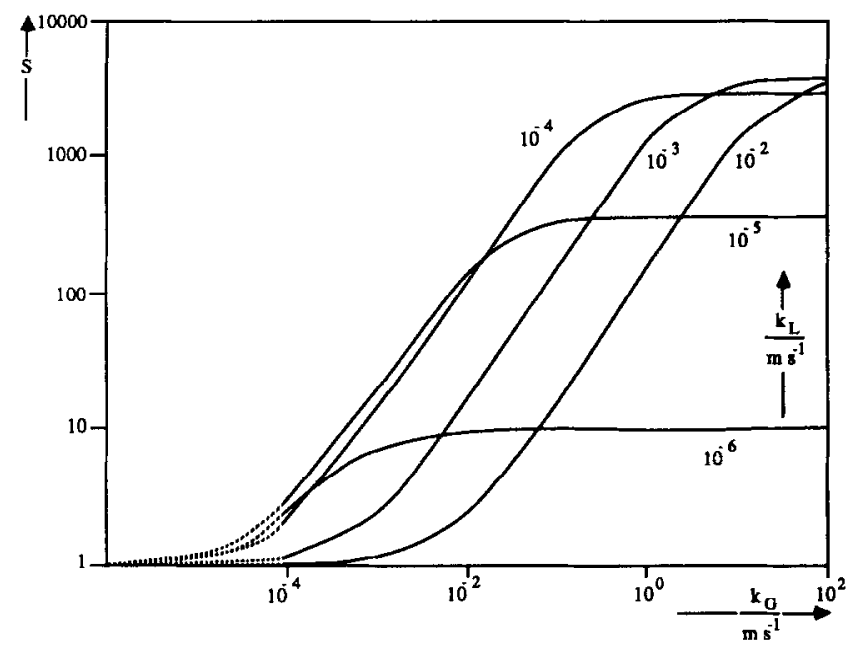

Figure 4 Selectivity factors for an aqueous MDEA solution calculated with the absorption model

interaction. The $S$-factor which can be attained in the region in between the asymptotics depends both on $k_{\mathrm{G}}$ and $k_{\mathrm{L}}$. Therefore, the application of Equation (19) to determine the selectivity of solvent can be substantially affected by the choice of the model reactor and its ratio to the mass transfer coefficients of the selected commercial reactor. In Figure $4 S$ is plotted as function of $k_{\mathrm{G}}$ with a constant $k_{\mathrm{L}}$ value for several amines. This figure clearly shows that a proper selection of the solvent can have a pronounced effect on the selectivity of the treating process.

From the outcome of the simulations (see Figures 3 and 4) it can be concluded that the selectivity of a solvent, determined with the aid of a model reactor, may lead to erroneous results if they are applied to reactors used in practical applications. Furthermore, there are two possible routes to improve the selectivity of a treating process towards $\mathrm{H}_{2} \mathrm{~S}$. First, selecting proper solvents and, second,

Table 3 Gas phase and liquid phase concentrations of the selectivity calculations

\begin{tabular}{|lr|}
\hline$\left[\mathrm{H}_{2} \mathrm{~S}\right]_{\text {gas, bulk }}$ & $1 \mathrm{~mol} \mathrm{~m}^{-3}$ \\
{$[\mathrm{CO}]_{\text {gas, bulk }}$} & $10 \mathrm{~mol} \mathrm{~m}^{-3}$ \\
Total [amine] & $2000 \mathrm{~mol} \mathrm{~m}^{-3}$ \\
$\mathrm{H}_{2} \mathrm{~S}$-liquid loading, $a_{\mathrm{H}_{2} \mathrm{~S}}$ & $10^{-2}$ \\
$\mathrm{CO}_{2}$-liquid loading, $a_{\mathrm{CO}_{2}}$ & $10^{-2}$ \\
\hline
\end{tabular}


by manipulation of the mass transfer coefficients as proposed originally by Danckwerts and Sharma ${ }^{26}$.

\section{Effect of small amounts of amine contaminants}

Another example of an application is the study of the effect of small amounts of contaminants in tertiary amine solutions. During the production of these amines or the regeneration of the loaded amine solutions at high temperatures, primary or secondary amines may be formed and therefore can be regarded as contaminants. These primary or secondary amines usually have a higher reactivity towards $\mathrm{CO}_{2}$ and thus affect the selectivity of the $\mathrm{H}_{2} \mathrm{~S}$ removal. In the present study the influence of a small amount of MEA ( $1 \mathrm{~mol} \%)$ in an aqueous MDEA solution has been simulated.

In Table 4 the input data of the calculations are presented. The values of the mass transfer coefficients have been ascertained with such values that the resistance in the gas phase can be completely neglected and the liquid phase mass Iransfer coefficient is similar to the values occurring in the stirred cells ${ }^{27}$. In Figure 5 the results of the calculations are presented, $S$ according to Equation (17) has been plotted as a function of the $\mathrm{H}_{2} \mathrm{~S}$ gas phase concentration for the pure MDEA and the MEAcontaminated MDEA solution. The $\mathrm{CO}_{2}$ gas phase concentration was equal to $10^{-1} \mathrm{~mol} \mathrm{~m}^{-3}$. For the pure MDEA solution the selectivity increases with decreasing $\mathrm{H}_{2} \mathrm{~S}$ concentration which is induced by the decrease of the diffusional limitation of the MDEA. This could be concluded from the calculated concentration profiles. A similar behaviour was observed for the contaminated MDEA solution; however the lines of $S$ have a point of intersection. At high $\mathrm{H}_{2} \mathrm{~S}$ gas phase concentration both MEA and MDEA are diffusion limited towards the interface and due to the higher equilibrium constant of MEA compared to MDEA, the absorption rate of $\mathrm{H}_{2} \mathrm{~S}$ under these conditions is more enhanced than for the pure MDEA solution. Decreasing the $\mathrm{H}_{2} \mathrm{~S}$ gas phase concentration diminishes the limitation of both amines and thus more fast reacting MEA becomes available for the reaction with $\mathrm{CO}_{2}$.

In Figure 6 the results of the calculations of the effect of the $\mathrm{CO}_{2}$ gas phase concentration on the selectivity factor have been presented with the $\mathrm{H}_{2} \mathrm{~S}$ gas phase concentration

Table 4 Input data for the simulations of the effect of small amounts of contaminants on the selectivity of the $\mathrm{H}_{2} \mathrm{~S}$ removal

\begin{tabular}{|ll|}
\hline$\left[\mathrm{H}_{2} \mathrm{~S}\right]_{\text {gas, bulk }}$ & $10^{-1}-10^{2} \mathrm{~mol} \mathrm{~m}^{-3}$ \\
{$\left[\mathrm{CO}_{2}\right]_{\text {gas, bulk }}$} & $10^{-1}-10^{2} \mathrm{~mol} \mathrm{~m}^{-3}$ \\
Total [amine] & $2000 \mathrm{~mol} \mathrm{~m}^{-3}$ \\
$\mathrm{H}_{2} \mathrm{~S}$-liquid loading, $\alpha_{\mathrm{H}_{2} \mathrm{~S}}$ & $10^{-3}$ \\
$\mathrm{CO}_{2}$-liquid loading, $\alpha_{\mathrm{CO}_{2}}$ & $2 \times 10^{-3}$ \\
$k_{\mathrm{L}}$ & $10^{-5} \mathrm{~ms}^{-1}$ \\
$k_{\mathrm{G}}$ & $10^{2} \mathrm{~ms}^{-1}$ \\
\hline
\end{tabular}

Table 5 Experimental conditions

\begin{tabular}{|llll|}
\hline & MEA & MDEA & MDEA + MEA \\
\hline Total [amine] $\left(\mathrm{mol} \mathrm{m}^{-3}\right)$ & 400 & 2000 & $2000+200$ \\
{$\left[\mathrm{CO}_{2}\right]_{\text {gas, bulk }}\left(\mathrm{mol} \mathrm{m}^{-3}\right)$} & $0-41$ & $0-41$ & $0-41$ \\
{$\left[\mathrm{H}_{2} \mathrm{~S}\right]_{\text {gas, bulk }}\left(\mathrm{mol} \mathrm{m}^{-3}\right)$} & $0-41$ & $0-41$ & $0-41$ \\
$k_{\mathrm{L}, \mathrm{CO}_{2}\left(\mathrm{~ms}^{-1}\right)}$ & $10^{-5}$ & $10^{-5}$ & $10^{-5}$ \\
$k_{\mathrm{L}, \mathrm{H}_{2} \mathrm{~s}}\left(\mathrm{~ms}^{-1}\right)$ & $10^{-5}$ & $10^{-5}$ & $10^{-5}$ \\
$k_{\mathrm{G}, \mathrm{CO}_{2}}\left(\mathrm{~ms}^{-1}\right)$ & $10^{-5}$ & $10^{-5}$ & $10^{-5}$ \\
$k_{\mathrm{G}, \mathrm{H}_{2} \mathrm{~S}}\left(\mathrm{~ms}^{-1}\right)$ & $10^{-5}$ & $10^{-5}$ & $10^{-5}$ \\
\hline
\end{tabular}

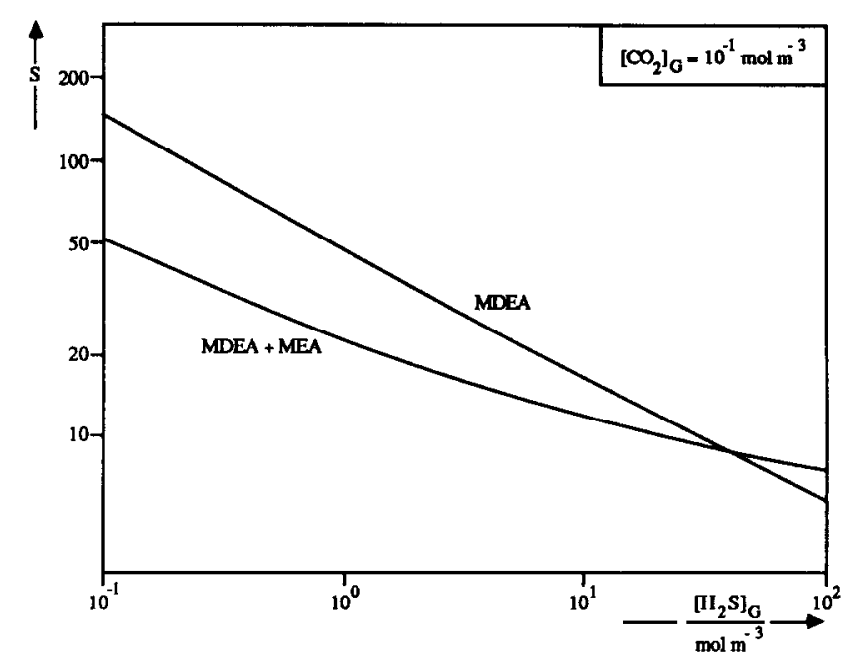

Figure 5 Simulated effect on $S$ of a small amount of MEA contamination in MDEA

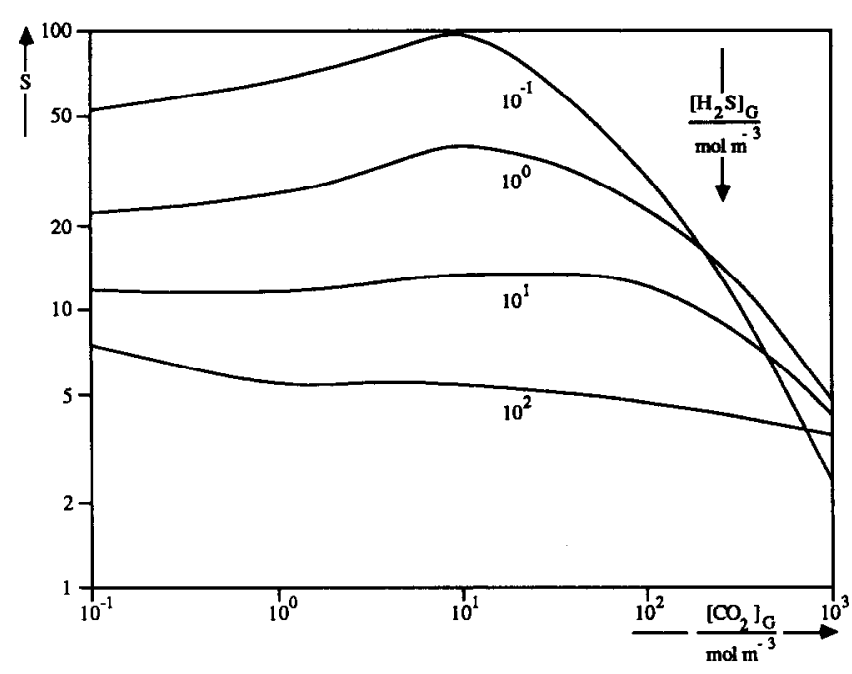

Figure 6 Simulated effect on $S$ of the driving forces for absorption for a MDEA solution contaminated with MEA

as parameter for the contaminated MDEA solution. For the highest $\mathrm{H}_{2} \mathrm{~S}$ concentration, $S$ increases with decreasing $\mathrm{CO}_{2}$ concentration; this can be easily explained from the fact that the diffusional limitation of the amines reduces. For the lower $\mathrm{H}_{2} \mathrm{~S}$ concentrations the explanation of the shape of the $S$-lines is more complex and, therefore, the concentration profiles must be studied. From these profiles it could be concluded that in going from low to high $\mathrm{CO}_{2}$ concentrations, the diffusional limitation of MEA increases leading to relatively lower absorption rates for $\mathrm{CO}_{2}$ and thus to better values for $S$. After reaching a maximum for $S$ the diffusional limitation of MDFA also becomes important; this results in a sharp reduction of the selectivity factor, both the absorption rates of $\mathrm{CO}_{2}$ and $\mathrm{H}_{2} \mathrm{~S}$ take place in the instantaneous reaction region. However, for very low values of $\mathrm{H}_{2} \mathrm{~S}$ concentration it is even possible that, due to the mutual interaction, hardly any $\mathrm{H}_{2} \mathrm{~S}$ is absorbed; this ultimately may lead to forced desorption of $\mathbf{H}_{2} \mathrm{~S}$.

\section{Experimental verification}

The model has been checked experimentally for the simultaneous absorption of $\mathrm{H}_{2} \mathrm{~S}$ and $\mathrm{CO}_{2}$ into aqueous solutions of MEA, MDEA and a mixture of MDEA-MEA. 
Two types of experiments were carried out: 1 , experiments with a gas mixture consisting only of $\mathrm{CO}_{2}$ and $\mathrm{H}_{2} \mathrm{~S}$; and, 2, a gas mixture consisting of either a constant $\mathrm{H}_{2} \mathrm{~S}$ or $\mathrm{CO}_{2}$ concentration with variation of the concentration of the remaining acid gas. All experiments were carried out for conditions with mutual interaction, although the phenomenon of forced desorption was expected not to occur. In Table 5 the conditions for the experiments are given.

In Figure 7 the results of the comparison of the simultaneous absorption of $\mathrm{CO}_{2}$ and $\mathrm{H}_{2} \mathrm{~S}$ in the MEA solution are presented for type 1 experiments. From this figure it can be concluded that the model can be used to estimate satisfactorily the observed absorption rates. The outcome of the experiments for the type 2 experiments for the MDEA solution are given in Figure 8. In Figure 9 the results for MDEA solution (experiment type 2), MDEAMEA mixture (experiment type 1), and DIPA solution (experiment type 1), are given and the average deviation from the experimentally observed absorption rates is less than $30 \%$. Moreover, an important part of the scatter can be attributed to experimental difficulties, especially for the type 2 experiments.

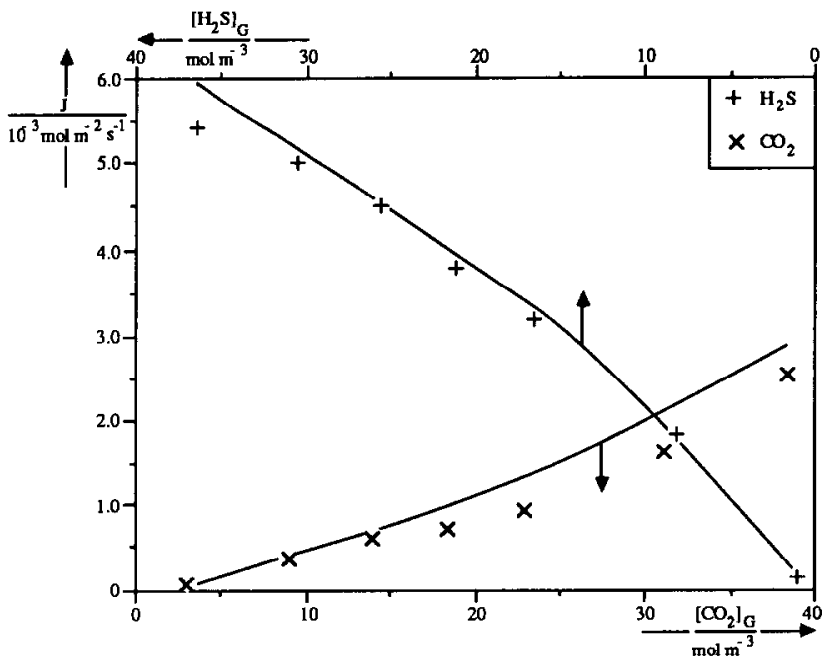

Figure 7 Experimental results and comparison with the absorption model for the simultaneous absorption of $\mathrm{H}_{2} \mathrm{~S}$ and $\mathrm{CO}_{2}$ in an aqueous MEA solution

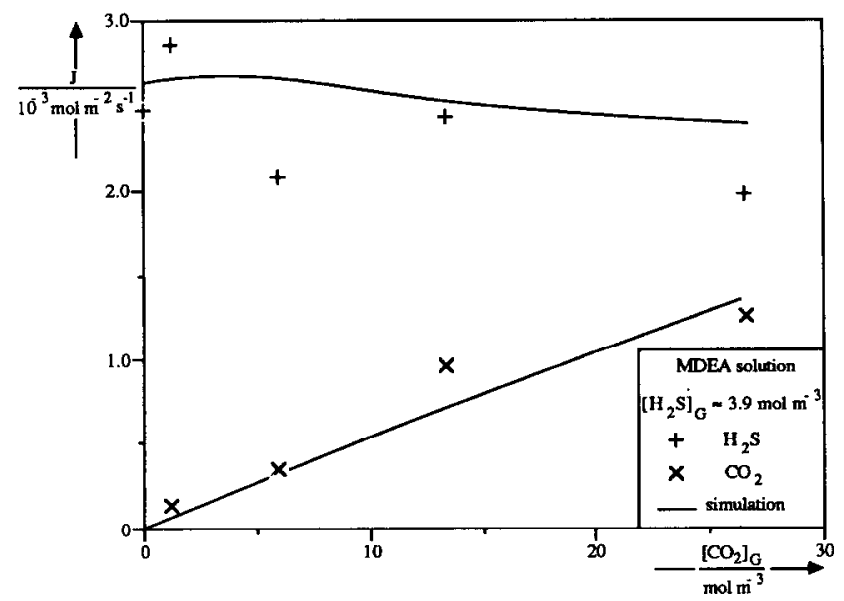

Figure 8 Experimental results and comparison with the absorption model for the simultaneous absorption of $\mathrm{H}_{2} \mathrm{~S}$ and $\mathrm{CO}_{2}$ in an aqueous MDEA solution

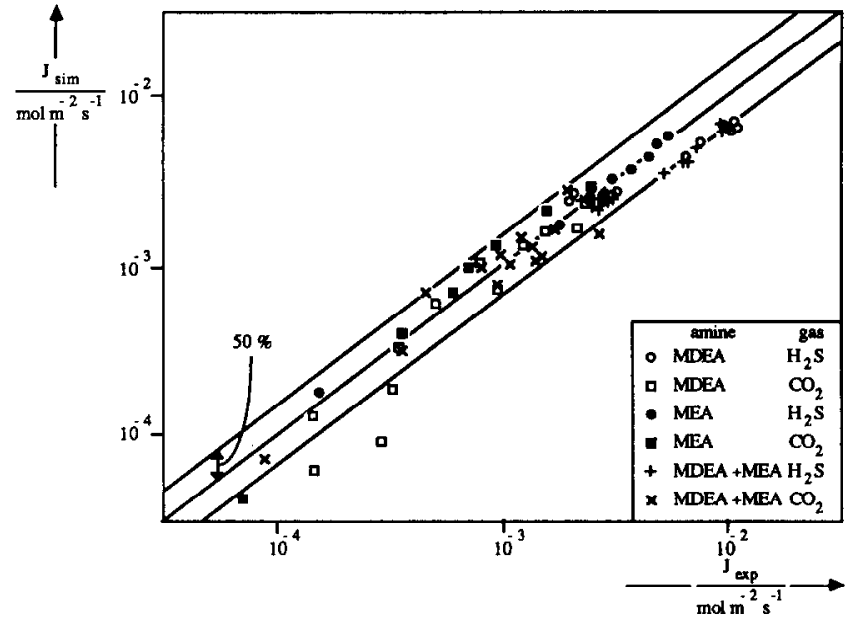

Figure 9 Comparisons between the measured and calculated absorption rates of $\mathrm{CO}_{2}$ and $\mathrm{H}_{2} \mathrm{~S}$ in the amine solutions studied

\section{Conclusions}

The absorption model developed in the present study can be used to calculate the absorption rates for simultaneous mass transfer accompanied by complex, parallel, reversible chemical reactions over a wide range of gas and liquid compositions, number of reactions and process conditions. The computation time required to carry out a calculation is acceptably short on a main frame and on a personal computer. This substantial reduction of the computation time without loss of accuracy was achieved by the implementation of an additional spatial transformation, derived from the one-dimensional unsteady diffusion process, and the development of special algorithms to solve the relevant equations. Moreover, no limitations remain in implementing the aforementioned mass transfer model into, for example, computational procedures for column design and simulations.

From the simulations carried out for the selectivity study, it can be concluded that the $S$-factors determined in a model reactor, according to Equation (19), can lead to an incorrect selection of the solvent for a specific treating process. This expression for the selectivity factor is only valid for a narrow range of experimental conditions and depends not only on the ratio $k_{\mathrm{G}} / k_{\mathrm{L}}$ but also on the magnitudes of these mass transfer parameters.

The numerical mass transfer model can be used to predict well the experimentally observed rates of the simultaneous absorption of $\mathrm{H}_{2} \mathrm{~S}$ and $\mathrm{CO}_{2}$ into aqueous solutions of amines and mixtures of amines. The experiments were carried out for conditions of mutual interaction, but the extreme interaction of forced desorption did not occur.

\section{Acknowledgements}

These investigations were supported by the Technology Foundation, Future Technical Science Branch of the Netherlands Organization for the Advancement of Pure Research (ZWO), and the Koninklijke/Shell Laboratorium Amsterdam.

\section{References}

1 Danckwerts, P.V. Gas-Liquid Reactions McGraw-Hill Book Company, London, UK (1970) 
2 Westerterp, K.R., van Swaaij, W.P.M. and Beenackers, A.A.C.M. Chemical Reactor Design and Operation Wiley \& Sons, New York, USA (1984)

3 van Krevelen, D.W. and Hoftijzer, P.J. Kinetics of gas-liquid reactions. Part I: general theory Rec Trav Chim (1948) 67 563-586

4 Onda, K., Sada, E., Kobayashi, T. and Fujine, M. Gas absorption accompanied by complex chemical reactions - I: reversible chemical reactions Chem Eng Sci (1970) 25 753-760

5 DeCoursey, W.J. Enhancement factors for gas absorption with reversible reaction Chem Eng Sci (1982) 37 1483-1489

6 Versteeg, G.F., Kuipers, J.A.M., van Beckum, F.P.H. and van Swaaij, W.P.M. Mass transfer with complex chemical reactions. I: reversible chemical reactions Chem Eng Sci (in press)

7 Perry, R.H. and Pigford, R.L. Kinetics of gas-liquid reactions. Simultaneous absorption and chemical reaction Ind Eng Chem (1953) 45 1247-1253

8 Secor, R.M. and Beutler, J.A. Penetration theory for diffusion accompanied by a reversible chemical reaction with generalized kinetics Am Inst Chem Eng (1967) 25 753-760

9 Cornelisse, R., Beenackers, A.A.C.M., van Beckum, F.P.H. and van Swaaij, W.P.M. Numerical calculation of simultaneous mass transfer of two gases accompanied by complex reversible reactions Chem Eng Sci (1980) 35 1245-1260

10 Blauwhoff, P.M.M. and van Swaaij, W.P.M. Simultaneous mass transfer of $\mathrm{H}_{2} \mathrm{~S}$ and $\mathrm{CO}_{2}$ with complex reactions in an aqueous di-isopropanola mine solution Chem Eng Proc (1985) 19 $67-83$

11 Versteeg, G.F., Kuipers, J.A.M., van Beckum, F.P.H. and van Swaaij, W.P.M. Mass transfer with complex chemical reactions. II: parallel reversible chemical reactions Chem Eng Sci (in press)

12 Baker, G.A. and Oliphant, T.A. An implicit, numerical method for solving the two-dimensional heat equation Quart Appl Math (1960) 17 361-373

13 Ramachandran, P.A. and Sharma, M.M. Simultaneous absorption of two gases Trans Inst Chem Eng (1971) 49 253-280

14 Cornelisse, R., Beenackers, A.A.C.M. and van Swaaij, W.P.M. Chem Eng Sci (1977) 331532

15 Hikita, H., Asai, S. and Ishikawa, H. Simultaneous absorption of two gases in a reactive liquid, one gas reacting instantaneously Chem Eng (1979) 18 169-172
16 Cornelissen, A.E. Simulation of absorption of $\mathrm{H}_{2} \mathrm{~S}$ and $\mathrm{CO}_{2}$ into aqueous alkanolamines in tray and packed columns Trans Inst Chem Eng (1980) 58 242-250

17 Higbie, R. The rate of absorption of a pure gas into a still liquid during short periods of exposure Trans Am Inst Chem Eng (1935) 35 36-60

18 Laddha, S.S., Diaz, J.M. and Danckwerts, P.V. The $\mathrm{N}_{2} \mathrm{O}$ analogy: the solubilities of $\mathrm{CO}_{2}$ and $\mathrm{N}_{2} \mathrm{O}$ in aqueous solutions of organic compounds Chem Eng Sci (1981) 36 479-482

19 Versteeg, G.F. and van Swaaij, W.P.M. Solubility and difffusivity of acid gases $\left(\mathrm{CO}_{2}, \mathrm{~N}_{2} \mathrm{O}\right)$ in aqueous alkanolamine solutions J Chem Eng Data (1988) 43 29-34

20 Blauwhoff, P.M.M. and van Swaaij, W.P.M. Gas-liquid equilibria between $\mathrm{H}_{2} \mathrm{~S}, \mathrm{CO}_{2}$ and aqueous amine solutions Proc 2nd Int Conf on Phase Equilibria and Fluid Properties in the Chem Ind EFCE Publication 11, Berlin, FRG (1980) p 78

21 Versteeg, G.F. and van Swaaij, W.P.M. On the kinetics of reactions between $\mathrm{CO}_{2}$ and alkanolamines both in aqueous and non-aqueous solutions. I: primary and secondary amines $C$ hem Eng Sci (1988) 43 573-585

22 Versteeg, G.F. and van Swaaij, W.P.M. On the kinetics of reactions between $\mathrm{CO}_{2}$ and alkanolamines both in aqueous and non-aqueous solutions. II: tertiary amines Chem Eng Sci (1988) $43587-591$

23 Blauwhoff, P.M.M., Versteeg, G.F. and van Swaaij, W.P.M. A study on the reaction between $\mathrm{CO}_{2}$ and alkanolamines in aqueous solutions Chem Eng Sci (1984) 39 207-225

24 McEwan, M.W. and Marmin, A. Developments in LNG treating Proceedings $L N G-6$ Vol. 2, Kyoto, Japan, (1980)

25 Kohl, A.L. and Riesenfeld, F.C. Gas Purification Gulf Publishing Company, Houston, USA (1985)

26 Danckwerts, P.V. and Sharma, M.M. The absorption of carbon dioxide into solutions of alkalis and amines Chem Eng (1966) 10 244-280

27 Versteeg, G.F., Blauwhoff, P.M.M. and van Swaaij, W.P.M. The effect of diffusivity on gas-liquid mass transfer in stirred vessels. Experiments at atmospheric and elevated pressures Chem Eng Sci (1987) 42 1103-1109

28 Blauwhoff, P.M.M., Kamphuis, B., van Swaaij, W.P.M. and Westerterp, K.R. Absorber design in sour natural gas treatment plants: impact of process variables on operation and economics Chem Eng Proc (1985) 19 1-25 